\title{
CARACTERIZAÇÃO BIOQUÍMICA E CINÉTICA DE LIPOXIGENASES DE FOLHAS DE SOJA SUBMETIDAS À REMOÇÃO DOS PRIMÓRDIOS FLORAIS
}

\author{
Biochemical and kinetic characterization of lipoxygenases from \\ soybean leaves submitted to the removal of floral primordial
}

\author{
Cristiano César de Araújo Ferreira ${ }^{1}$, Maria Goreti de Almeida Oliveira ${ }^{2}$, \\ Christiano Vieira Pires ${ }^{3}$, Joel Antônio de Oliveira ${ }^{4}$, Anderson Martins Pilon ${ }^{3}$, \\ Fabrício Tadeu de Almeida ${ }^{5}$, Maria Helena Nasser Brumano ${ }^{6}$, Maurilio Alves Moreira ${ }^{2}$
}

\section{RESUMO}

O uso da soja [Glycine max (L.) Merrill] na alimentação humana tem encontrado dificuldades devido ao seu sabor característico (beany flavor), que é derivado da ação das lipoxigenases (EC 1.13.11.12). Ao contrário das lipoxigenases de sementes de soja, que têm sido extensivamente estudadas, a diversidade e características das lipoxigenases de folhas não estão totalmente elucidadas. Sabe-se que além de sua atividade catalítica, as lipoxigenases de folhas estão envolvidas no armazenamento temporário de nitrogênio e na resposta da planta ao estresse. Com o objetivo de investigar o efeito da remoção dos primórdios florais na atividade das lipoxigenases de folhas de soja, foram utilizados dois genótipos de soja: IAC-100, uma variedade com presença de lipoxigenases na semente e IAC-100 TN, uma linhagem com ausência completa de lipoxigenases na semente. Por meio de dados da cinética enzimática, foram constatados dois picos mais acentuados de atividade em $\mathrm{pH}$ 5,0 e 6,5, com temperatura ótima de $25^{\circ} \mathrm{C}$. Para ambos os genótipos, as atividades foram maiores nos tratamentos que nos respectivos controles. Os valores de $\mathrm{K}_{\mathrm{M}}$ app aos 16 dias, nas plantascontrole, foram semelhantes para os dois genótipos, sugerindo não haver influência da manipulação genética das lipoxigenases na semente em relação à expressão dos genes que codificam as lipoxigenases de folhas. No entanto, os valores de $\mathrm{K}_{\mathrm{M} \text { app }}$ foram diferentes entre a fase vegetativa e a reprodutiva, em ambos genótipos, indicando pools distintos de isoenzimas lipoxigenases entre as duas fases.

Termos para indexação: Folhas de soja, lipoxigenase, parâmetros cinéticos, proteína vegetativa, estresse, Glycine max.

\section{ABSTRACT}

The use of soybean [Glycine max (L.) Merrill] as human food has been encountered difficulties due to beany flavor. The beany flavour is originated from lipoxygenases (EC 1.13.11.12). Soybean seed lipoxygenases have been extensively studied, however, the diversity and characteristics of lipoxygenases present in leaves are still being studied. Besides its catalytic activity, lipoxygenases from soybean leaves have been implicated in temporary nitrogen storage and response to stress. The primary objective of this research was to investigate the effect of floral primordial elimination (sink deprivation) on soybean leaves lipoxygenases activity. Two different genotypes differing in the presence (IAC-100) or absence (IAC-100 TN) of LOX in their seeds were used. The enzymatic kinetics analysis showed two pronounced peaks of activity at $\mathrm{pH} 5$ and 6.5 , with optimal temperature of $25^{\circ} \mathrm{C}$. The $\mathrm{K}_{\mathrm{M}}$ app values were similar for both genotypes suggesting that there was not effect of genetic manipulation of seeds lipoxygenases on genes expression that code for leave lipoxygenases. However, the $\mathrm{K}_{\mathrm{M}}$ app values were different between the vegetative and reproductive development stage, suggesting that there are differents pool of lipoxygenases between the two stages.

Index terms: Soybean leaves, lipoxygenases, kinetic parameters, vegetative protein, stress, Glycine max.

(Recebido para publicação em 18 de novembro de 2002 e aprovado em 25 de dezembro de 2002)

\footnotetext{
1. Pós-Graduado em Agroquímica, DBB/BIOAGRO/UFV, 36571-000 - Viçosa, MG.

2. Professor do Departamento de Bioquímica e Biologia Molecular/BIOAGRO, UFV, malmeida@mail.ufv.br.

3. Pós-Graduando do Departamento de Bioquímica e Biologia Molecular, UFV.

4. Professor do Departamento de Química, UFV.

5. Estudante de Iniciação Científica, Departamento de Bioquímica e Biologia Molecular, UFV.

6. Pesquisadora do Laboratório de Enzimologia, BIOAGRO/UFV.
} 


\section{INTRODUÇÃO}

Lipoxigenases (EC 1.13.11.12) são uma classe de enzimas que catalisam a adição do oxigênio molecular ao sistema pentadieno dos ácidos graxos polinsaturados, formando hidroperóxidos dos ácidos graxos correspondentes, e contêm ferro não-hêmico, o qual é necessário para sua atividade catalítica (AXELROD et al., 1981; VICK e ZIMMERMAN, 1987; BUNKER et al., 1995).

As lipoxigenases vegetais utilizam ácido linolênico (C18:3) e/ou ácido linoléico (C18:2) como substrato e estão envolvidas na biossíntese de compostos regulatórios, tais como o ácido traumático e o ácido jasmônico (ANDERSON et al., 1989; FARMER e RYAN, 1992; BUNKER et al., 1995), crescimento e desenvolvimento (HILDEBRAND, 1989; SIEDOW, 1991), senescência (ROUET-MAYER et al., 1992), germinação de sementes (PARK et al., 1994), resistência a insetos e patógenos (CROFT et al., 1993; BOHLAND et al., 1997; SILVA et al., 2001), resposta a ferimento (VIEIRA et al., 2001) e reserva vegetativa (TRANBARGER et al., 1991; BUNKER et al., 1995; STEPHENSON et al., 1998).

Quando tecidos de plantas são danificados por patógenos ou mecanicamente (estresse), ocorre uma degradação seqüencial de lipídeos em que os produtos primários da reação das lipoxigenases, os hidroperóxidos podem ser metabolizados por duas vias enzimáticas principais: hidroperóxido liase e hidroperóxido ciclase.

A hidroperóxido liase produz aldeídos de seis carbonos, como o trans-2-hexenal (composto característico do sabor e odor de frutos e folhas) e a traumatina. Os aldeídos formados pela ação da lipoxigenase possivelmente inibem o crescimento de fungos, insetos e protozoários (CROFT et al., 1993) e podem agir como um sinal químico na atração do inimigo natural do herbívoro para a planta danificada (PARÉ e TUMLINSON, 1997).

A hidroperóxido ciclase produz o ácido 12oxo-fitodienóico que, após uma redução e três $\beta$ oxidações, dá origem ao ácido jasmônico, o qual está envolvido nos processos de desenvolvimento da planta, assim como na resposta da planta a injúria e a patógenos, por meio da indução de genes que codificam para inibidores de proteases (FARMER e RYAN, 1992; CROFT et al., 1993).

Há pesquisas por meio das quais demonstra-se que outros órgãos, além das sementes, são capazes de sintetizar proteínas de reserva (STASWICK, 1990). Folhas de soja e órgãos em desenvolvimento acumulam três polipeptídeos de aproximadamente 27, 29 e $94 \mathrm{kD}$, os quais constituem uma classe de proteínas denominadas proteínas de reserva vegetativa (PRV), durante o crescimento vegetativo. A PRV de aproximadamente $94 \mathrm{kD}$ são lipoxigenases (TRANBARGER et al., 1991) e se acumulam temporariamente em células especializadas do mesofilo paraveinal - uma camada única de células que interconecta o sistema vascular da folha com o mesofilo parenquimático e esponjoso.

Neste trabalho investigou-se o comportamento bioquímico e cinético do pool de lipoxigenases foliares, com a remoção dos primórdios florais (dreno) de dois genótipos de soja: IAC -100, variedade de soja normal, com as lipoxigenases nas sementes, e IAC-100 TN, genótipo manipulado geneticamente, com ausência completa de lipoxigenases na semente.

\section{MATERIAL E MÉTODOS}

\section{Material genético}

Foram utilizadas plantas de soja (Glycine max (L.) Merrill) da variedade IAC-100 e do genótipo com ausência de lipoxigenases nas sementes (IAC-100 TN), desenvolvido pelo Programa de Melhoramento da Qualidade da Soja do BIOAGRO/UFV. As plantas foram cultivadas em vasos com capacidade para 4,0 kg de solo em condições de casa-de-vegetação, com 3 repetições.

A fonte de isoenzimas lipoxigenases foi a última folha trifoliolar de plantas de soja no estádio reprodutivo de desenvolvimento (FEHR e CAVINESS, 1977). Os três folíolos foram coletados, congelados em nitrogênio líquido e armazenados $\mathrm{a}-80^{\circ} \mathrm{C}$.

\section{Retirada dos primórdios florais}

As plantas de soja nos estádios reprodutivos (FEHR e CAVINESS, 1977) tiveram os primórdios florais retirados diariamente, com auxílio de uma pinça, durante um período de duas semanas, a partir da antese (SARAVITZ e SIEDOW, 1995). Após 4, 8, 12 e 16 dias, os folíolos da última folha trifoliolar, completamente expandidos, foram coletados, para posterior obtenção de extratos foliares. Também foram coletadas as folhas no tempo "zero" (no início da antese). Em plantas-controle, a vagem desenvol- 
veu-se naturalmente, uma vez que não foram removidos os primórdios florais. Os folíolos da última folha trifoliolar, completamente expandidos, também foram coletados.

\section{Obtenção de extratos foliares}

O preparo do extrato bruto foi realizado a $4^{\circ} \mathrm{C}$, de acordo com o método de Ohta et al. (1986), com a seguinte modificação: tampão fosfato de sódio 50 mmol.L $\mathrm{L}^{-1}$, pH 6,5.

\section{Determinação da atividade de lipoxigenases}

A atividade de lipoxigenase sobre o ácido linoléico foi determinada segundo o método descrito por Axelrod et al. (1981). Os ensaios foram realizados a $25^{\circ} \mathrm{C}$.

\section{Determinação da atividade de lipoxigenases em vários pH}

$\mathrm{O}$ efeito do $\mathrm{pH}$ sobre a atividade de lipoxigenases foi determinado a $234 \mathrm{~nm}$, pelo método descrito por Axelrod et al. (1981), em vários valores de $\mathrm{pH}$, na temperatura de $25^{\circ} \mathrm{C}$. Os sistemastampão utilizados foram os seguintes: ácido cítrico/ $\mathrm{Na}_{2} \mathrm{HPO} 4 \mathrm{pH} 2 ; 2,5$, ácido cítrico/citrato de sódio pH 3;3,5, acetato de sódio pH 4,0;4,5; citrato de sódio $\mathrm{pH} 5,0 ; 5,5$; fosfato de sódio $\mathrm{pH} 6,0 ; 6,5 ; 7,0$; Tris$\mathrm{HCl} \mathrm{pH} 7,5 ; 8,0 ; 8,5$ e borato de sódio $\mathrm{pH}$ 9,$0 ; 9,5 ; 10,0$.

\section{Determinação da atividade de lipoxigenases em várias temperaturas}

Foi determinada a taxa de oxidação do ácido linoléico catalisada pelas lipoxigenases a 20, 25, 30, $35,40,45$ e $50^{\circ} \mathrm{C}$. Foram utilizados banho-maria, bem como espectrofotômetro com sistema de temperatura controlada. Os ensaios foram realizados em pH 6,5.

Determinação dos parâmetros cinéticos de lipoxigenases foliares de soja

Os parâmetros cinéticos, constante de Michaelis-Menten aparente $\left(K_{M}\right.$ app $)$ e velocidade máxima aparente $\left(\mathrm{V}_{\max \text { app }}\right)$ no estado estacionário foram obtidos por meio de regressão não-linear, empregando-se o programa de computação Enzifitter (LEATHERBARROW, 1987).

\section{RESULTADOS E DISCUSSÃO}

Efeito do $\mathrm{pH}$ sobre a atividade de lipoxigenases de folhas de soja

Há dois picos mais acentuados a pH 5,0 e 6,5 nos tratamentos e nos respectivos controles, indicando a presença de isoenzimas (Figura 1). Saravitz e Siedow (1995) também encontraram duas classes distintas de isoenzimas lipoxigenases de folhas de soja, uma com ponto isoelétrico neutro e outra ácido. A atividade enzimática foi maior nos tratamentos (com a retirada dos primórdios florais) do que nos controles (sem a retirada dos primórdios florais), em ambos os genótipos. Esse fato também foi observado por Bunker et al. (1995), os quais verificaram aumento no nível de mRNAs de múltiplas formas de lipoxigenase em resposta à remoção diária das vagens. A variedade IAC100 , com presença de lipoxigenases na semente, apresentou maior atividade em $\mathrm{pH}$ 6,5, que a linhagem IAC-100 $\mathrm{TN}$, sem a presença de lipoxigenases na semente.

Efeito da temperatura sobre a atividade de lipoxigenases de folhas de soja

O pico mais acentuado de atividade foi a $25^{\circ} \mathrm{C}$, para ambos os genótipos e seus respectivos controles (Figura 2). As atividades de lipoxigenases foram maiores nos tratamentos do que nos controles, em ambos os genótipos analisados, a várias temperaturas. Esse resultado está de acordo com Stephenson et al. (1998), que verificaram aumento de sete vezes no nível de transcritos da família multigênica das lipoxigenases e que isoformas específicas participaram no armazenamento temporário e partição de assimilados e nitrogênio, com a remoção do dreno (primórdios florais).

\section{Parâmetros cinéticos $K_{M}$ app e $V_{\text {máx app }}$}

Os gráficos de Michaelis-Menten de atividade de lipoxigenase sobre o ácido linoléico, da variedade IAC100 e do genótipo IAC-100 TN, nos tempos de 12 dias após a remoção dos primórdios florais, encontram-se representados nas Figuras 3 e 4, respectivamente. Nessas figuras, encontram-se também inseridos os gráficos de Lineweaver-Burk.

Nos dois tratamentos, ambos os genótipos apresentaram gráficos com curva hiperbólica, mostrando que o pool de lipoxigenases de folhas em plantas de soja submetidas à remoção dos primórdios florais segue a cinética de Michaelis-Menten, na faixa de concentração de substrato analisada. Os gráficos dos demais tempos 
analisados apresentaram perfis semelhantes (dados nãomostrados).

Observa-se que nas plantas-controle, com o passar dos dias, ocorreu uma diminuição dos valores de $\mathrm{K}_{\mathrm{M}}$ app, para ambos os genótipos, exceto aos 16 dias para o IAC-100 TN, no qual houve um aumento comparado aos 12 dias (Tabelas 1 e 2). Já nas plantas tratadas, aos 4 dias após remoção dos primórdios florais, houve di- minuição dos valores de $\mathrm{K}_{\mathrm{M}}$ app; aos 8 dias, os valores aumentaram; aos 12 dias, diminuíram, e aos 16 dias, aumentaram em ambos os genótipos. Todavia, foram sempre menores que os valores de $K_{M}$ app das plantas-controle, indicando mudanças no "pool" de lipoxigenases entre a fase de desenvolvimento vegetativo (tempo 0) e fase de desenvolvimento reprodutivo da planta de soja.

(a)

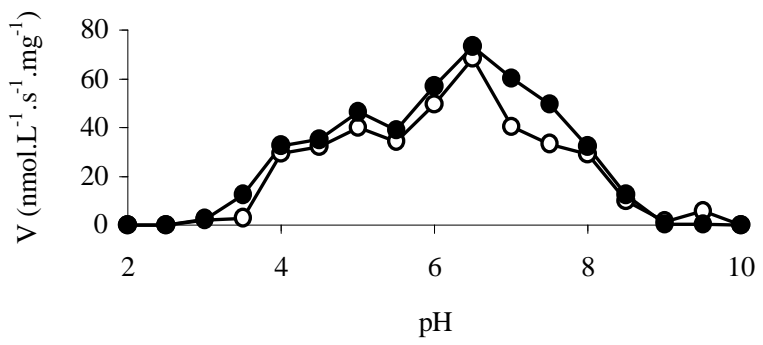

(b)

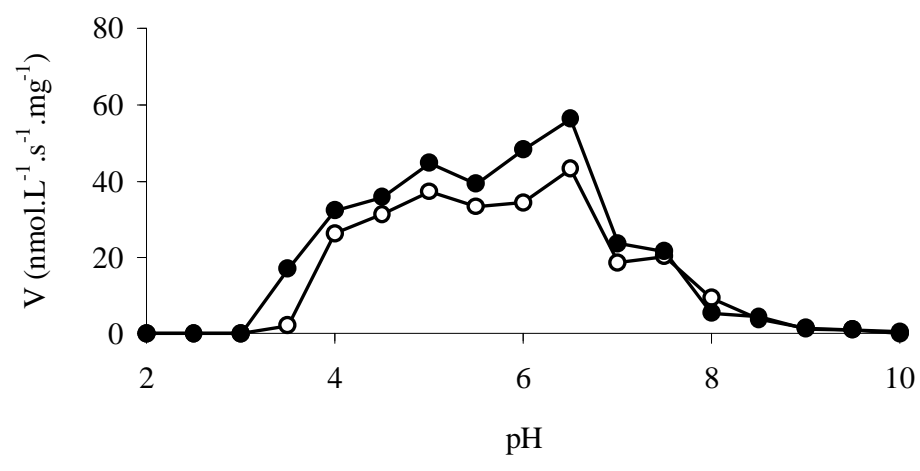

(——) Atividade enzimática de plantas tratadas.

(- - ) Atividade enzimática de plantas-controle.

FIGURA 1 - Atividade de lipoxigenases (V) de folhas de soja sobre o ácido linoléico, da variedade IAC-100 (a) e do genótipo IAC-100 TN (b), coletados 16 dias após a retirada dos primórdios florais, e seus respectivos controles, em vários $\mathrm{pH}$, na temperatura de $25^{\circ} \mathrm{C}$. 
(a)

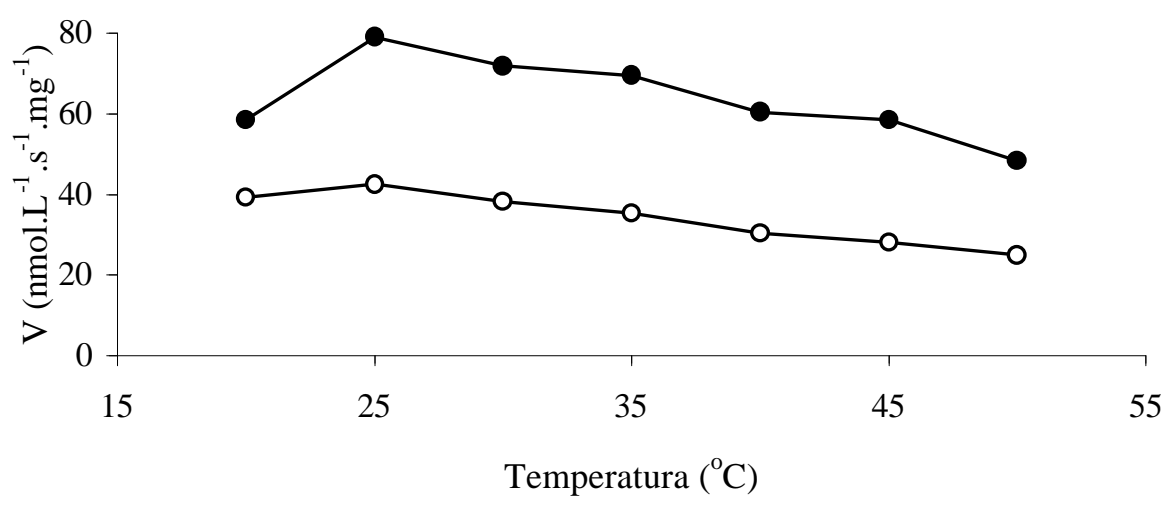

(b)

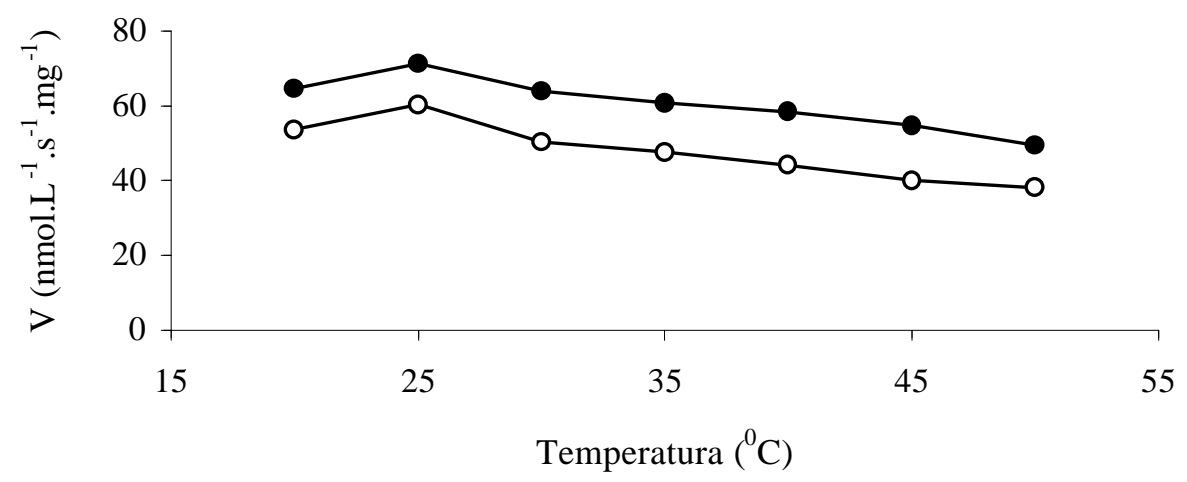

(——) Atividade enzimática de plantas tratadas.
$(-\ldots$ Atividade enzimática de plantas-controle.

FIGURA 2 - Atividade de lipoxigenases (V) de folhas de soja sobre o ácido linoléico, da variedade IAC-100 (a) e do genótipo IAC-100 TN (b), coletados 16 dias após a retirada dos primórdios florais, e seus respectivos controles, em várias temperaturas, em $\mathrm{pH}$ 6,5.

Observa-se também que o genótipo IAC-100 TN (sem lipoxigenases nas sementes) apresentou um valor de $\mathrm{K}_{\mathrm{M} \text { app }}$ e $\mathrm{V}_{\text {max app }}$ de $89,78 \%$ e $88,89 \%$ respectivamente superior ao da variedade IAC-100. Verifica-se que o genótipo IAC-100 TN mostrou uma maior redução nos valores de $\mathrm{K}_{\mathrm{M} \text { app }}$ com o passar dos dias, tanto no con- trole como nas plantas tratadas. Contudo, aos 16 dias nas plantas-controle, esses valores foram semelhantes ao do genótipo IAC-100. Portanto, parece que a presença ou ausência de lipoxigenases nas sementes influenciou na resposta fisiológica das lipoxigenases da folha até os 12 dias, após remoção dos primórdios florais. 


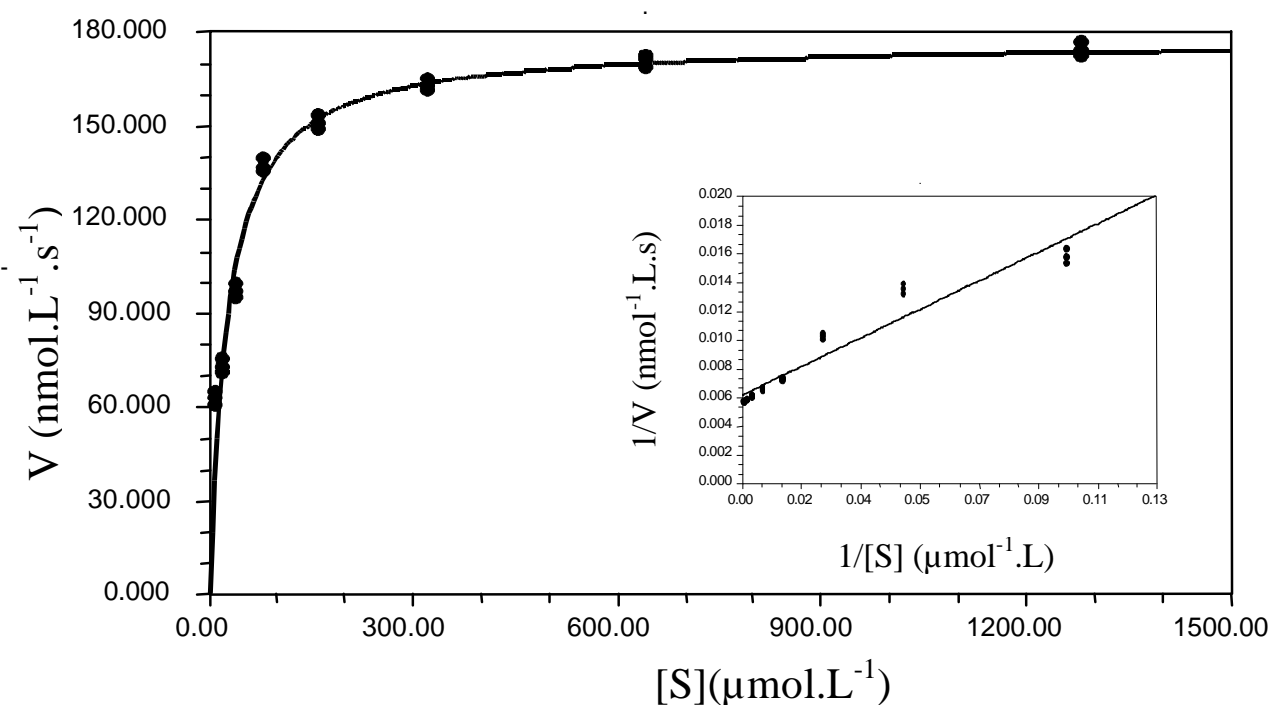

FIGURA 3 - Gráfico de Michaelis-Menten [V - (velocidade de reação) versus S - (concentração de substrato)] para a formação de hidroperóxido do ácido linoléico, catalisada pelas lipoxigenases de folhas de soja da variedade IAC-100 coletadas 12 dias após a remoção dos primórdios florais. Inserção: gráfico de LineweaverBurk.

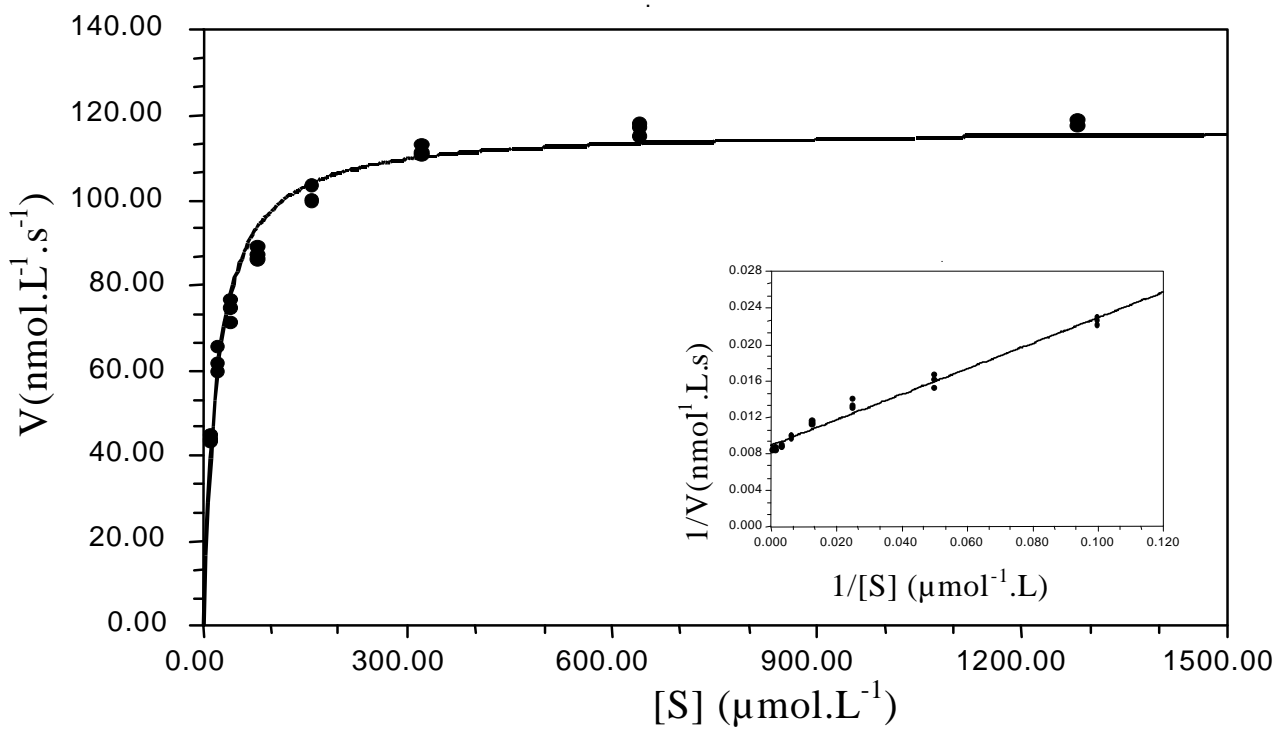

FIGURA 4 - Gráfico de Michaelis-Menten [V - (velocidade de reação) versus S - (concentração de substrato)] para a formação de hidroperóxido do ácido linoléico, catalisada pelas lipoxigenases de folhas de soja do genótipo IAC-100 TN coletadas 12 dias após a remoção dos primórdios florais. Inserção: gráfico de LineweaverBurk.

Ciênc. agrotec., Lavras, v. 28, n. 2, p. 261-268, mar./abr., 2004 
TABELA 1 - Parâmetros cinéticos de lipoxigenases de folhas* de soja da variedade IAC-100** sobre o ácido linoléico.

\begin{tabular}{|c|c|c|c|c|}
\hline \multirow[b]{2}{*}{$\begin{array}{c}\text { Dias após } \\
\text { remoção do dreno }\end{array}$} & \multicolumn{2}{|c|}{ Controle } & \multicolumn{2}{|c|}{ Tratamento } \\
\hline & $\begin{array}{c}\mathbf{K}_{\mathrm{M} \text { app }} \\
\mu \mathrm{mol.L^{-1 }}\end{array}$ & $\begin{array}{c}V_{\text {maxapp }} \\
\mu \operatorname{mol}_{\text {.L }}{ }^{-1} \cdot \mathrm{s}^{-1}\end{array}$ & $\begin{array}{c}\mathrm{K}_{\mathrm{M} \text { app }} \\
\mu \mathrm{mol.L^{-1 }}\end{array}$ & $\begin{array}{c}V_{\text {maxapp }} \\
\mu_{\text {mol.L }} \mathbf{L}^{-1} \cdot \mathbf{s}^{-1}\end{array}$ \\
\hline 0 & $109,72 \pm 8,3$ & $0,09 \pm 0,01$ & $109,72 \pm 8,3$ & $0,09 \pm 0,01$ \\
\hline 4 & $58,07 \pm 5,1$ & $0,13 \pm 0,03$ & $61,13 \pm 6,1$ & $0,14 \pm 0,02$ \\
\hline 8 & $51,64 \pm 4,8$ & $0,10 \pm 0,01$ & $94,43 \pm 7,3$ & $0,10 \pm 0,02$ \\
\hline 12 & $27,09 \pm 3,2$ & $0,18 \pm 0,04$ & $31,89 \pm 4,4$ & $0,15 \pm 0,03$ \\
\hline 16 & $25,77 \pm 3,6$ & $0,12 \pm 0,01$ & $65,43 \pm 5,8$ & $0,15 \pm 0,02$ \\
\hline
\end{tabular}

*Última folha trifoliolar, no estádio reprodutivo de planta, submetida à retirada dos primórdios florais. **Os dados referem-se à média de 3 repetições \pm desvio-padrão.

TABELA 2 - Parâmetros cinéticos de lipoxigenases de folhas* de soja do genótipo IAC-100 TN** sobre o ácido linoléico.

\begin{tabular}{|c|c|c|c|c|}
\hline \multirow[b]{2}{*}{$\begin{array}{c}\text { Dias após } \\
\text { remoção do dreno }\end{array}$} & \multicolumn{2}{|c|}{ Controle } & \multicolumn{2}{|c|}{ Tratamento } \\
\hline & $\begin{array}{c}\mathbf{K}_{\mathrm{M} \text { app }} \\
\mu \mathrm{mol.L^{-1 }}\end{array}$ & $\begin{array}{c}V_{\text {max app }} \\
\mu m o l . L^{-1} \cdot s^{-1}\end{array}$ & $\begin{array}{c}\mathbf{K}_{\mathrm{M} \text { app }} \\
\mu \mathrm{mol.L^{-1 }}\end{array}$ & $\begin{array}{c}V_{\text {max app }} \\
\mu \text { mol. }^{-1} \cdot \mathrm{s}^{-1}\end{array}$ \\
\hline 0 & $208,23 \pm 17,6$ & $0,17 \pm 0,03$ & $208,23 \pm 17,6$ & $0,17 \pm 0,03$ \\
\hline 4 & $36,30 \pm 3,8$ & $0,11 \pm 0,01$ & $36,92 \pm 4,5$ & $0,07 \pm 0,01$ \\
\hline 8 & $31,74 \pm 4,2$ & $0,12 \pm 0,02$ & $38,08 \pm 5,4$ & $0,15 \pm 0,02$ \\
\hline 12 & $19,68 \pm 3,2$ & $0,18 \pm 0,02$ & $35,80 \pm 3,9$ & $0,13 \pm 0,01$ \\
\hline 16 & $26,43 \pm 2,9$ & $0,12 \pm 0,03$ & $57,65 \pm 6,4$ & $0,10 \pm 0,01$ \\
\hline
\end{tabular}

*Última folha trifoliolar, no estádio reprodutivo de planta, submetida à retirada dos primórdios florais.

**Os dados referem-se à média de 3 repetições \pm desvio-pad rão.

\section{CONCLUSÃO}

Diferentes lipoxigenases foliares estão presentes em plantas de soja, com e sem a retirada dos primórdios florais. O aumento da atividade de lipoxigenases com a remoção dos primórdios florais é, provavelmente, decorrente do estresse, que causa ativação da "via das lipoxigenases" e/ou do acúmulo das proteínas de reserva vegetativa, em que fazem parte membros da família da lipoxigenase. Os valores de $\mathrm{K}_{\mathrm{M} \text { app, }}$ aos 16 dias, nas plantas-controle, foram semelhantes para os dois genótipos, sugerindo não haver influência da manupulação genética das lipoxigenases na semente em relação à expressão dos genes que codificam as lipoxigenases de folhas.

\section{AGRADECIMENTOS}

Este trabalho foi financiado pela FAPEMIG (Fundação de Amparo à Pesquisa do Estado de Minas Gerais), e pelo CNPq.

\section{REFERÊNCIAS BIBLIOGRÁFICAS}

ANDERSON, J. M.; SILATRO, S. R.; KLAUER, S. F.; FRANCESCHI, V. R. Jasmonic acid-dependent increases in the level of vegetative storage proteins in soybean. Plant Science, Shannon, v. 62, p. 45-52, 1989.

AXELROD, B.; CHEESBROUGH, T. M.; LAASKO, S. Lipoxygenases from soybeans. Methods Enzymology, [S.1.], v. 71, p. 441-451, 1981. 
BOHLAND, C.; BALKENHOHL, T.; LOERS G.; FEUSSNER, I.; GRAMBOW, H. J. Differential induction of lipoxygenases isoforms in wheat upon treatment with rust fungus elicitor, chitin oligossaccharides, chitosan, and methyl jasmonate. Plant Physiology, Washington, v. 114, p. 679-685, 1997.

BUNKER, T. W.; KOETJE, D. S.; STEPHENSON, L. C.; CREELMAN, R. A.; MULLET, J. E.; GRIMES, H. D. Sink limitation induces the expression of multiple soybean lipoxygenase mRNAs while the endogenous jasmonic acid level remains low. Plant Cell, Tissue and Organ Culture, Dordrecht, v. 7, p. 1319-1331, 1995.

CROFT, K. P. C.; JÜTTNER, F.; SLUSARENKO, A. J. Volatile products of the lipoxygenase pathway evolved from Phaseolus vulgaris (L.) leaves inoculated with Pseudomonas syringae pv phaseolicola. Plant Physiology, Washington, v. 101, p. 13-24, 1993.

FARMER, E. E.; RYAN, C. A. Octadecanoid precursors of jasmonic acid activate the syntesis of wound-inducible proteinase inhibitors. Plant Cell, Tissue and Organ Culture, Dordrecht, v. 4, p. 129-134, 1992.

FEHR, W. R.; CAVINESS, C. E. Stages of soybean development. Ames: Cooperative Extension Service-lowa State University, 1977. 11 p. (Special Report, 80).

HILDEBRAND, D. F. Lipoxygenases. Physiologia Plantarum, Copenhagen, v. 76, p. 249-253, 1989.

LEATHERBARROW, R. J. Enziffiter manual. Biosoftware, London, p. 13-42, 1987.

OHTA, H.; IDA, S.; MIKAMI, B.; MORITA, Y. Changes in lipoxygenase components of rice seedling during germination. Plant Cell Physiology, Washington, v. 22 , p. $911-918,1986$.

PARÉ, P. W.; TUMLINSON, J. H. De novo biosyntesis of volatiles inducible by insect herbivory in cotton plants. Plant Physiology, Washington, v. 114, p. 11611167, 1997.

PARK, T. K.; HOLLAND, M. A.; LASKEY, J. G.; POLACCO, J. C. Germination - associated lipoxygenases transcripts persist in maturing soybean plants and are induced by jasmonate. Plant Science, Shannon, v. 96, p. 109-117, 1994.
ROUET-MAYER, M.; BUREAU, J.; LAURIERI, C. Identification and characterization of lipoxygenase isoforms in senescing carnation petals. Plant Physiology, Washington, v. 98, p. 971-978, 1992.

SARAVITZ, D. M.; SIEDOW, J. N. Changes during leaf development, after wounding, and following reproductive sink removal. Plant Physiology, Washington, v. 107, p. 535-543, 1995.

SIEDOW, J. N. Plant lipoxygenase: struture and function. Annual Review Plant Physiology Plant Molecular Biology, Washington, v. 42, p. 145-188, 1991.

SILVA, M. D.; OLIVEIRA, M. G. A.; LANNA, A. N.; PIRES, C. V.; PIOVESAN, N. D.; JOSE, I. C.; BATISTA, R. B.; BARROS, E. G.; MOREIRA, M. A. Caracterização da via das lipoxigenases em plantas de soja resitentes e succeptiveis a Diaphorte phaseolorum F. SP. Meridionalis, agente causal do cancro da haste. Brazilian Journal of Plant Physiology, São Paulo, v. 13, n. 3, p. 316-328, 2001.

STASWICK, P. E. Novel regulation of vegetative storage protein genes. The Plant Cell, [S.1.], v. 2, p. 1-6, 1990.

STEPHENSON, L. C.; BUNKER, T. W.; DUBBS, W. E.; GRIMES, H. D. Specifc soybean lipoxygenases localize to discrete subcellular compartments and their mRNAs are differentially regulated by source-sink status. Plant Physiology, Washington, v. 116, p. 923-933, 1998.

TRANBARGER, T. J.; FRANCESCHI, V. R.; HILDEBRAND, D. F.; GRIMES, H. D. The soybean 94-kilodalton vegetative storage protein is a lipoxygenase that is localized in paraveinal mesophyll cell vacuoles. Plant Cell, Tissue and Organ Culture, Dordrecht, v. 3, p. 973-987, 1991.

VICK, B.; ZIMMERMAN, D. C. Oxidative systems for modification of fatty acids: the lipoxygenase pathway. In: STUMPF, P. K.; CONN, E. E. (Eds.). The biochemistry of plants. Orlando: Academic, 1987. v. 9, p. 53-97.

VIEIRA, A. A.; OLIVEIRA, M. G. A.; JOSE, I. C.; PIOVESAN, N. D.; REZENDE, S. T.; MOREIRA, M. A.; BARROS, E. G. Biochemical evaluation of lipoxygenase pathaway of soybean plants submitted to wounding. Brazilian Journal of Plant Physiology, São Paulo, v. 13, n. 1, p. 5-12, 2001. 